\title{
Hepcidin in hemodialysis patients and its association with anemia and serum iron indices
}

\author{
Farahnaz Ghahramanfard $^{\oplus}$, Maliheh Yarmohamadi $^{* *}{ }^{\circledR}$, Raheb Ghorbani $^{3}$, Vahid Semnani ${ }^{4}$, Arash \\ Mirzaei $^{4}$, Maryam Ghushchian Chubmasgedi ${ }^{4}$ \\ ${ }^{1}$ Cancer Research Center (CRC), Semnan University of Medical Sciences, Semnan, Iran \\ ${ }^{2}$ Department of Internal Medicine, Faculty of Medicine, Semnan University of Medical Sciences, Semnan, Iran \\ ${ }^{3}$ Social Determinants of Health Research Center, Department of Epidemiology and Biostatistics, Semnan University of Medical Sciences, \\ Semnan, Iran \\ ${ }^{4}$ Department of Pathology, Faculty of Medicine, Semnan University of Medical Sciences, Semnan, Iran
}

\section{AR T I C L E I N F O}

Article Type:

Original

\section{Article History:}

Received: 9 October 2018

Accepted: 25 December 2018

Published online: 29 January 2019

\section{Keywords:}

Hepcidin-25

Hemodialysis

Anemia

Chronic kidney disease

Erythropoietin

End-stage renal disease

\begin{abstract}
A B S T R A C T
Introduction: Anemia is one of the most common complications in dialysis patients. Deficiency of erythropoietin is the most common cause of anemia in dialysis patients. Chronic kidney disease (CKD) patients have a negative iron balance. Hepcidin is an antibacterial peptide that its synthesis is controlled by the iron surface and inflammatory markers and plays an important role in iron hemostasis in hemodialysis patients. In the presence of anemia, the level of hepcidin in normal individuals is reduced. Therefore, the normal level of hepcidin in CKD individuals is considered high due to their anemia level, while, the level of hepcidin is reduced after dialysis.

Objectives: We aimed to study the level of hepcidin-25 in hemodialysis patients and its relationship with anemia and serum iron indices.

Patients and Methods: In a cross-sectional study, 70 patients who fulfilled inclusion criteria enrolled in the study. Serum hepcidin 25 was measured by ELISA method. At the same time, blood samples were taken to measure other indices including iron, ferritin, C-reactive protein (CRP), total iron binding capacity (TIBC) and albumin. Hepcidin-25 levels compared with other mentioned parameters. Statistical analysis was done in SPSS 18.0 software.

Results: No significant relationship between inflammatory cytokines, TIBC and CRP and erythrocyte sedimentation rate (ESR) with hepcidin levels was detected. Additionally, relationship between serum iron, ferritin and hepcidin levels was not significant $(P>0.05)$. Conclusion: Assessment of hepcidin 25 level for inflammation and iron status does not seem to be helpful for anemia management in hemodialysis patients.
\end{abstract}

\section{Implication for health policy/practice/research/medical education:}

This paper has a research implication for anemia management in hemodialysis patients.

Please cite this paper as: Ghahramanfard F, Yarmohamadi M, Ghorbani R, Semnani V, Mirzaei A, Ghushchian Chubmasgedi M. Hepcidin in hemodialysis patients and its association with anemia and serum iron indices. J Renal Inj Prev. 2019; 8(2):146-150.

DOI: 10.15171/jrip.2019.27

\section{Introduction}

Anemia is a common complication in dialysis patients. Among different types of anemia, normocytic normochromic and mild hypochromic anemias, which originate from insufficient erythrocyte production, occur more prevalently in these patients $(1,2)$. Many factors contribute to these anemias, including erythropoietin, iron deficiency, blood loss, dialysis, chronic inflammation, and factors which negatively affect erythropoiesis $(3,4)$. Previous studies have been addressed "erythropoietin" deficiency as the most prevalent cause of anemia in dialysis patients $(5,6)$. Regarding the anemia in patients with chronic kidney disease (CKD), increased blood loss either through gastrointestinal tract or due to pathogenic causes can lead to a negative iron balance, resulting in reduced levels of ferritin, iron as well as iron saturation to less than $16 \%$ (7). Decreased intestinal iron absorption in dialysis patients have been clearly reported in some studies $(8,9)$.

Hepcidin is an antibacterial peptide which has been 
regulated by iron and inflammatory markers, and plays a key role in iron hemostasis in dialysis patients. The peptide is produced in the liver and acts as a normal regulator of hemostasis and a negative regulator of iron absorption in normal conditions. High levels of hepcidin inhibit iron absorption from duodenum and iron release from macrophages (10). It is generally accepted that oral iron intake can increase the levels of hepcidin in normal individuals. Whereas, iron deficiency can severely affect the levels of hepcidin in mice (11). Acute type II inflammatory reactants, associated with interleukin 6, are shown to be responsible for hepcidin production. In anemia, erythropoietin and hypoxia resulted in increasing of iron absorption while reducing hepcidin production $(12,13)$. The occurrence of anemia in normal individuals decreases hepcidin levels. Therefore, with regard to the level of anemia, normal levels of hepcidin are considered high in patients with CKD. Moreover, in healthy erythropoietin-receiving individuals, the levels of hepcidin decrease to $70 \%-75 \%$ in 24 hours (14).

Studies have been shown that hepcidin is independently related to creatinine, triglycerides, and the remaining kidney function in dialysis patients. Hepcidin is increased in dialysis patients, but there is no relationship between increased levels of hepcidin and the level of interleukin-6 or unresponsiveness to treatment. However, this increase reverses following treatment with erythropoietin (15). Furthermore, the level of hepcidin decreases after dialysis $(16,17)$. Thus, dialysis and inflammation have different effects on reducing or increasing of hepcidin in dialysis patients due to anemia.

\section{Objectives}

This study aimed to determine the level of hepcidin in dialysis patients and its relation with anemia, treatmentresistant anemia, and the levels of ferritin, albumin, and inflammatory factors for finding new therapeutic approaches (anti-hepcidin antibody) regarding treatment of anemia and end-stage renal disease (ESRD) in hemodialysis patients.

\section{Patients and Methods}

\section{Patients}

This study was conducted on over 18 years old hemodialysis patients in Kowsar hospital of Semnan, Iran. The only inclusion criterion was dialysis from at least three times a month to three times a week. The exclusion criteria were the history of sustained cardiovascular disease, acute infection, active inflammatory disease, pregnancy, receiving blood in the last 6 months, any evidence of active or hidden (internal) bleeding, liver disease, any type of malignancy, and using immunosuppressive drugs. The study objectives were described to patients before enrollment in the study and written informed consent was obtained from all participants. The patients were asked to stop iron compounds 2 weeks before the study. In order to eliminate interaction between hemodialysis and hepcidin, blood samples were collected before dialysis. Hepcidin-25 was measured with ELISA. Other indices including iron, ferritin, albumin, iron saturation, reticulocyte count, and CRP (C-reactive protein) were also measured (Latex agglutination). Finally, the relationship between hepcidin-25 and the mentioned parameters was statistically analyzed.

A total of $2 \mathrm{~mL}$ blood was collected from fasted patients in anticoagulant-containing tubes; and serum was separated through retaining them at room temperature for 20 minutes and centrifugation at $3000 \mathrm{rpm}$ for 10 minutes. The samples supernatant (serum) was carefully removed and kept at $-80^{\circ} \mathrm{C}$. Twenty-four hours before measurement, samples were transferred to $2-8^{\circ} \mathrm{C}$. Hepcidine-25 was measured using the ELISA kit.

\section{Ethical issues}

Human rights were respected in accordance with the Helsinki Declaration 1975, as revised in 1983. The informed consent was taken from the hemodialysis patients. The study was approved by ethics committee of Semnan University of Medical Sciences (Ethical cod\# IR.SEMUMS.REC.1394.116). This article resulted from a general practitioner thesis by Arash Mirzaei (research project \# 915) funded by deputy of research, Semnan University of Medical Sciences.

\section{Statistical analysis}

The data were statistically analyzed with IBM SPSS 22 (SPSS Inc., Chicago, IL) through Kolmogorov-Smirnov test and $t$ test (or Mann-Whitney U, Pearson's, or Spearman's correlation coefficient tests) and the results were reported as mean \pm standard deviation. The significant level was considered as $5 \%$.

\section{Results}

Hepcidin-25 was measured in 69 patients admitted for hemodialysis to Kowsar hospital of Semnan, Iran; 58\% of them $(n=40)$ were male and the rest were female. The level of hepcidin-25 was $1486.1 \pm 1659.2 \mathrm{pg} / \mathrm{dL}$ (with a median of $1361 \mathrm{pg} / \mathrm{dL}$ ) in males and $1722.9 \pm 1821.7 \mathrm{pg} / \mathrm{dL}$ (with a median of $1603.7 \mathrm{pg} / \mathrm{dL}$ ) in females. The results showed no significant difference in the mean of hepcidin-25 between males and females $(P=0.580)$. The mean age of patients was $62.3 \pm 14.9$ years ranging from 29 to 95 years. No significant correlation was found between the levels of hepcidin-25 and age of patients $(P=0.604, \mathrm{r}=-0.064)$. CRP was negative in $78 \%(n=54)$ and positive in $21.7 \%$ of the patients ( $4.3 \%$ weak positive, $8.7 \%$ positive, $8.8 \%$ $\mathrm{CRP}++)$. There was no significant difference between CRP-negative and CRP-positive patients regarding hepcidin-25 level distribution $(P=0.556)$.

Total iron binding capacity (TIBC) was normal (250- 
$400 \mathrm{mcg} / \mathrm{dL})$ in $71 \%$ of patients $(\mathrm{n}=49),<250 \mathrm{mcg} /$ $\mathrm{dL}$ in $2.9 \%$, and $>400 \mathrm{mcg} / \mathrm{dL}$ in the rest. There was no significant correlation between TIBC and hepcidin levels $(P=0.229, r=-0.147)$ (Table 1$)$.

\section{Iron}

The level of iron was normal in $53.6 \%(n=37)$ of patients and low in the rest $(46.4 \%)$. None of the patients had an iron level of higher than normal. There was no significant correlation between serum iron and hepcidin-25 levels $(P$ $=0.289, r=0.130$; Table 2).

\section{Ferritin}

The level of ferritin was in the normal range (20-110 $\mathrm{ng} / \mathrm{dL}$ in women and $20-250 \mathrm{ng} / \mathrm{dL}$ in men) in $30.4 \%$ of the patients $(n=21)$, and high in the rest. There was no significant correlation between ferritin and hepcidin levels $(P=0.379, r=0.108$; Table 3$)$.

\section{Erythrocyte sedimentation rate}

Erythrocyte sedimentation rate (ESR) was in the normal range in $34.8 \%(\mathrm{n}=24)(<15 \mathrm{~h} / \mathrm{mm}$ in men and $<20 \mathrm{~h} / \mathrm{mm}$ in women) and abnormal in $65.2 \%$ of patients. There was no significant correlation between ESR and hepcidin-25 levels $(P=0.060, r=0.228)$.

\section{Albumin}

The level of albumin was normal $(3.5-5 \mathrm{~g} / \mathrm{dL})$ in $68.1 \%$ ( $\mathrm{n}=47)$ and $<3.5$ in $31.9 \%$ of patients. There was no significant correlation between serum albumin and hepcidin levels $(P=0.367, r=0.110)$.

\section{Ferritin}

According to the results, the level of ferritin was in normal range (20-110 in women and 20-250 in men) in 30.4\% (n $=21$ ) of patients and was high in the rest of the patients. There was no significant correlation between serum ferritin and hepcidin levels $(P=0.379, r=0.108$; Table 3$)$.

\section{Discussion}

In this study, hepcidin-25 level was evaluated in 69 hemodialysis patients. According to the results, there was no significant relationship between hepcidin and the levels of inflammatory factors, albumin, iron, ferritin, and TIBC. Moreover, 58\% of the subjects were males and the rest were females with a mean hepcidin level of 1486.1. There was no significant difference in the distribution of hepcidin between men and women.

In contrast with our findings, Brătescu et al (18) found that the level of hepcidin was significantly lower in men than women. However, gender has not been considered in other results reported in the literature. Both studies had different results with the present study due to small sample size. Furthermore, no significant relationship was observed between age and hepcidin levels among different age groups in this study.

There was also no significant relationship between inflammatory indicators of CRP and ESR with hepcidin, which was in accordance with the study conducted by Abbasi Larki et al (19). They did not find any association between hepcidin, ESR and CRP. Additionally, Kuragano et al (20) found similar results. Likewise, Kato et al (21) showed that CRP has no relationship with hepcidin. Similar results have been found by van der Putten et al (22).

However, our results were in contrast with the studies of Malyszko et al (23), Uehata et al (24), and Brătescu et al (18). They studied the relationship between hepcidin and inflammation indicators such as CRP. These contradictory results may arise from small sample size of similar studies, which should be addressed in the future studies.

No significant correlation was found between TIBC values and hepcidin levels in the present research. This was consistent with the studies of Uehata et al and Abbasi Larki et al $(19,24)$. They also did not find any association between iron stores and hepcidin $(19,24)$.

There was no significant correlation between levels of

Table 1. Compare of hepcidin levels in patients in term of levels of TIBC

\begin{tabular}{|c|c|c|c|c|c|c|c|}
\hline TIBC (mcg/dL) & No. of samples & Mean & Standard deviation & Median & Inter-quartile range & $P$ value & Correlation coefficient \\
\hline$<250$ & 2 & 462.5 & 67.2 & 462.5 & - & & \\
\hline $250-400$ & 49 & 1652.9 & 1801.1 & 650.0 & 3200 & 0.229 & -0.147 \\
\hline$>400$ & 18 & 1527.2 & 1585.0 & 572.5 & 3124 & & \\
\hline
\end{tabular}

Table 2. Comparing hepcidin levels in patients regarding the level of iron

\begin{tabular}{lccccccc}
\hline Iron level & No. of samples & Mean & SD & Median & Inter-quartile range & $\boldsymbol{P}$ value & Correlation coefficient \\
\hline Less than Normal & 32 & 1305.1 & 1499.7 & 498.0 & 1788 & 0.289 \\
Normal & 37 & 1828.2 & 1876.8 & 695.0 & 3240 & 0.130 \\
\hline
\end{tabular}

Table 3. Mean, standard deviation, range and inter-quartile range of hepcidin-25 levels regarding ferritin levels

\begin{tabular}{lccccccc}
\hline Ferritin level $(\mathbf{n g} / \mathbf{d L})$ & No. of samples & Mean & SD & Median & Inter-quartile range & $\boldsymbol{P}$ value & Correlation coefficient \\
\hline Less than Normal & 21 & 1369.6 & 1536.9 & 495.0 & 2458 & \multirow{2}{*}{0.379} \\
Normal & 48 & 1680.1 & 1801.7 & 665.0 & 3165 & 0.108 \\
\hline
\end{tabular}


albumin and hepcidin, which was in accordance with the study reported by Pezeshki et al (19).

In addition, there was no significant relationship between the levels of serum iron and hepcidin, which is consistent with the study of Pezeshki et al (19). However, our findings were in contrast to the study by Malyszko et al. They showed that decreased serum iron can lead to an increase in hepcidin. This inconsistency may arise from the lack of subjects with low serum iron level which can affect levels of hepcidin (23).

Our results showed their similarity with Pezeshki et al, Taheri et al, Uehata et al, Vander Putten et al, Hilde et al, and Tessitore et al, while they could not find any relationship between hepcidin and ferritin (19, 22, 24- 27).

Wagner et al showed that high ferritin levels can affect hepcidin, which seems distinctly different from our research. However, this inconsistency can arise from high sample size in the present study (29). In general, it can be concluded that there was no significant relationship between inflammatory factors, levels of albumin, iron saturation, TIBC, and ferritin with hepcidin.

\section{Conclusion}

There was no significant relationship between serum hepcidin-25 level with inflammatory factors, serum albumin level, iron saturation, TIBC, and ferritin in hemodialysis patients. So assessment of hepcidin 25 level for inflammation and iron status does not seem to be helpful for anemia management in hemodialysis patients.

\section{Limitations of the study}

A limitation in this study was relatively low sample size. The same study in larger sample size is suggested.

\section{Authors' contribution}

AM and MY searched the literature. FGh VS prepared the primary draft. FGh and MY performed first the edition. MY conducted final edition. VS did laboratory tests. RGh performed statistical analysis. All authors wrote and signed the final paper.

\section{Conflicts of interest}

The authors declared no competing interests.

\section{Ethical considerations}

Ethical issues (including plagiarism, data fabrication, double publication) have been completely observed by the authors.

\section{Funding/Support}

This study was funded by deputy of research, Semnan University of Medical Sciences.

\section{References}

1. Paganini EP.Overview of anemia associated with chronic renal disease: primary and secondary mechanisms. Semin
Nephrol. 1989;9:3-8

2. Obrador GT, Ruthazer R, Arora P, Kausz AT, Pereira BJ. Prevalence of and factors associated with suboptimal care before initiation of dialysis in the United States. J Am Soc Nephrol. 1999;10:1793-800.

3. Fisher JW, Hatch FE, Roh BL, Allen RC, Kelley BJ. Erythropoietin inhibitor in kidney extracts and plasma from anemic uremic human subjects. Blood. 1968;31:44052.

4. Radtke HW, Rege AB, Lamarche MB, Bartos D, Bartos F, Campbell RA, Fisher JW. Identification of spermine as an inhibitor of erythropoiesis in patients with chronic renal failure. J Clin Invest. 1981;67:1623-9. doi: 10.1172/ JCI110197.

5. Eschbach JW, Mladenovic J, Garcia JF, Wahl PW, Adamson JW. The anemia of chronic renal failure in sheep. Response to erythropoietin-rich plasma in vivo. J Clin Invest. 1984;74(2):434-41. doi: 10.1172/JCI111439.

6. Erslev AJ, Besarab A. The rate and control of baseline red cell production in hematologically stable patients with uremia. J Lab Clin Med. 1995;126:283-6.

7. Finch CA. Erythropoiesis, erythropoietin, and iron. Blood. 1982;60:1241-6.

8. Kooistra MP, Niemantsverdriet EC, van Es A, MolBeermann NM, Struyvenberg A, Marx JJ. Iron absorption in erythropoietin-treated haemodialysis patients: effects of iron availability, inflammation and aluminium. Nephrol Dial Transplant. 1998;13:82-8. doi: 10.1093/ndt/13.1.82.

9. Goch J, Birgegård G, Danielson BG, Wikström B. Iron absorption in patients with chronic uremia on maintenance hemodialysis and in healthy volunteers measured with a simple oral iron load test. Nephron. 1996;73:403-6. doi: $10.1159 / 000189100$.

10. Ganz T, Jung G, Naeim A, Ginzburg Y, Pakbaz Z, Walter PB, Kautz L, Nemeth E. Immunoassay for human serum erythroferrone. Blood. 2017;130:1243-6. doi: 10.1182/ blood-2017-04-777987.

11. Nicolas G1, Bennoun M, Porteu A, Mativet S, Beaumont C, Grandchamp B, et al. Severe iron deficiency anemia in transgenic mice expressing liver hepcidin. Proc Natl Acad Sci U S A. 2002;99:4596-01. doi: 10.1073/pnas.072632499.

12. Nicolas G, Chauvet C, Viatte L, Danan JL, Bigard X, Devaux I, et al. The gene encoding the iron regulatory peptide hepcidin is regulated by anemia, hypoxia, and inflammation. J Clin Invest. 2002;110:1037-44. doi: 10.1172/JCI15686.

13. Peyssonnaux C, Zinkernagel AS, Schuepbach RA, Rankin E, Vaulont S, Haase VH, et al. Regulation of iron homeostasis by the hypoxia-inducible transcription factors (HIFs). J Clin Invest. 2007;117:1926-32. doi: 10.1172/JCI31370.

14. Ashby DR, Gale DP, Busbridge M, Murphy KG, Duncan ND, Cairns TD, et al. Erythropoietin administration in humans causes a marked and prolonged reduction in circulating hepcidin. Haematologica. 2010;95:505-8. doi: 10.3324/haematol.2009.013136.

15. Ashby DR, Gale DP, Busbridge M, Murphy KG, Duncan ND, Cairns TD, et al. Plasma hepcidin levels are elevated but responsive to erythropoietin therapy in renal disease. Kidney Int. 2009;75:976-81. doi: 10.1038/ki.2009.21.

16. Zaritsky J, Young B, Gales B, Wang HJ, Rastogi A, Westerman M, et al. Salusky. Reduction of serum hepcidin by hemodialysis in pediatric and adult patients Clin J Am Soc Nephrol. 2010;5:1010-4. doi: 10.2215/CJN.08161109. 17. Weiss G, Theurl I, Eder S, Koppelstaetter C, Kurz K, 
Sonnweber T, et al. Serum hepcidin concentration in chronic haemodialysis patients: associations and effects of dialysis, iron and erythropoietin therapy. Eur J Clin Invest. 2009;39:883-90. doi: 10.1111/j.1365-2362.2009.02182.x.

18. Brătescu LO, Bârsan L, Munteanu D, Stancu S, Mircescu G. Is hepcidin-25 a clinically relevant parameter for the iron status in hemodialysis patients? J Ren Nutr. 2010;20:S77-83. doi: 10.1053/j.jrn.2010.06.006.

19. Abbasi Larki R, Seifi S, Lesan Pezeshki M. The relationship between pro-hepcidin and serum biochemical parameters in chronic hemodialysis patients: a study on 54 patients. Tehran Univ Med J. 2011;68(11):681-685.

20. Kuragano T, Shimonaka Y, Kida A, Furuta M, Nanami M, Otaki Y, et al. Determinants of hepcidin in patients on maintenance hemodialysis: role of inflammation. Am J Nephrol. 2010;31:534-40. doi: 10.1159/000312381.

21. Kato A, Tsuji T, Luo J, Sakao Y, Yasuda H, Hishida A. Association of Prohepcidin and hepcidin-25 with erythropoietin response and ferritin in hemodialysis patients. Am J Nephrol 2008;28:115-121. doi: 10.1159/000109968.

22. van der Putten K, Jie KE, van den Broek D, Kraaijenhagen RJ, Laarakkers C, Swinkels DW, et al. Hepcidin-25 is a marker of the response rather than resistance to exogenous erythropoietin in chronic kidney disease/chronic heart failure patients. Eur J Heart Fail. 2010;12:943-50. doi: 10.1093/eurjhf/hfq099.

23. Malyszko J, Malyszko JS, Kozminski P, Mysliwiec M. Type of renal replacement therapy and residual renal function may affect prohepcidin and hepcidin. Ren Fail. 2009;31:876-83. doi: $10.3109 / 08860220903216071$.
24. Uehata T, Tomosugi N, Shoji T, Sakaguchi Y, Suzuki A, Kaneko T, et al. Serum hepcidin-25 levels and anemia in non-dialysis chronic kidney disease patients: a crosssectional study. Nephrol Dial Transplant. 2012; 27:1076-83. doi: $10.1093 /$ ndt/gfr431.

25. Taheri N, Roshandel G, Mojerloo M, Hadad M, Mirkarimi $\mathrm{H}$, Nejad RK, et al. Comparison of serum levels of hepcidin and pro-hepcidin in hemodialysis patients and healthy subjects. Saudi J Kidney Dis Transpl. 2015;26:34-8. doi: 10.4103/1319-2442.148730

26. van der Weerd NC, Grooteman MP, Bots ML, van den Dorpel MA, den Hoedt CH, Mazairac AH, et al. Hepcidin-25 in chronic hemodialysis patients is related to residual kidney function and not to treatment with erythropoiesis stimulating agents. PLoS One. 2012;7:e39783. doi: 10.1371/ journal.pone.0039783.

27. Peters HP, Laarakkers CM, Swinkels DW, Wetzels JF. Serum hepcidin-25 levels in patients with chronic kidney disease are independent of glomerular filtration rate. Nephrol Dial Transplant. 2010;25:848-53. doi: 10.1093/ndt/gfp546.

28. Tessitore N, Girelli D, Campostrini N, Bedogna V, Pietro Solero G, Castagna A, et al. Hepcidin is not useful as a biomarker for iron needs in haemodialysis patients on maintenanceerythropoiesis-stimulating agents. Nephrol Dial Transplant. 2010;25:3996-4002. doi: 10.1093/ndt/ gfq321.

29. Wagner M, Ashby DR, Kurtz C, Alam A, Busbridge M, Raff $\mathrm{U}$, et al. Hepcidin-25 in diabetic chronic kidney disease is predictive for mortality and progression to end stage renal disease. PLoS One. 2015;10:e0123072. doi: 10.1371/journal. pone. 0123072 .

Copyright (C) 2019 The Author(s); Published by Nickan Research Institute. This is an open-access article distributed under the terms of the Creative Commons Attribution License (http://creativecommons.org/licenses/by/4.0), which permits unrestricted use, distribution, and reproduction in any medium, provided the original work is properly cited. 